\title{
Manufacturing Experience for the LHC Inner Triplet Quadrupole Cables
}

\author{
R.M.Scanlan ${ }^{1}$, H.C.Higley ${ }^{1}$, R.Bossert ${ }^{2}$, J.Kerby ${ }^{2}$, A.K.Ghosh ${ }^{3}$, M.Boivin ${ }^{4}$, and T.Roy ${ }^{4}$ \\ ${ }^{1}$ Lawrence Berkeley National Laboratory, 1 Cyclotron Rd., Berkeley, CA 94720 USA \\ ${ }^{2}$ Fermi National Accelerator Laboratory, P.O.Box 500, Batavia, IL 60510 USA \\ ${ }^{3}$ Brookhaven National Laboratory, Bldg 902A, Upton, NY 11973 USA \\ ${ }^{4}$ New England Electric Wire, 130 N. Main St., Lisbon, NH 03585
}

\begin{abstract}
The design for the U.S. LHC Inner Triplet Quadrupole magnet requires a 37 strand (inner layer) and a 46 strand (outer layer) cable. This represents the largest number of strands attempted to date for a production quantity of Rutherford-type cable. The cable parameters were optimized during the production of a series of short prototype magnets produced at FNAL. These optimization studies focused on critical current degradation, dimensional control, coil winding, and interstrand resistance. After the $R \& D$ phase was complete, the technology was transferred to NEEW and a new cabling machine was installed to produce these cables. At present, about 60 unit lengths, out of 90 required for the entire production series of magnets, have been completed for each type of cable. The manufacturing experience with these challenging cables will be reported. Finally, the implications for even larger cables, with more strands, will be discussed.
\end{abstract}

Index Terms--Cables, NbTi, Superconducting Magnets

\section{INTRODUCTION}

$T^{\mathrm{n}}$ he Inner Triplet Quadrupoles for the LHC Interaction Regions must provide a minimum gradient of $215 \mathrm{~T} / \mathrm{m}$ in a $70 \mathrm{~mm}$ bore. Two magnet designs are being manufactured. For the Q1 and Q3 components, KEK [1] have made a 4layer magnet using $11 \mathrm{~mm}$ wide cable. For the Q2a and Q2b components, Fermilab [2] as part of the US-LHC Accelerator Project is producing magnets based on a 2-layer design using $15.4 \mathrm{~mm}$ wide cable, that is the focus of this paper. A constraint imposed in the initial design was that both inner layer and outer layer cable were required to be the same width, so that a joint between inner and outer layer cables could be made within the straignt section of the outer coil body, several turns from the pole. As the program evolved, a more conventional design was adopted in which the inner-toouter cable splice was made between the pole turns of the inner and outer coils, situated in the pole region near the lead end. However, the cable manufacturing program was underway, so the two cables were maintained at the same width. Another design requirement was that the cables utilize wherever possible the existing inventory of inner and outer wire produced for the SSC project.

The resulting cables represent a significant extension of the current state of the art, in particular for the outer layer cable. One measure of the relative difficulty of producing a given cable design is the aspect ratio (cable width/cable thickness). The outer cable has an aspect ratio of 13.4, compared with the FNAL Low Beta Quadrupole cable ratio of 10.9, the SSC dipole outer cable ratio of 10.1 and the LHC outer cable ratio of 10.2. Thus, an extensive R\&D program was undertaken in order to optimize the cabling parameters and to verify that this highly aspected cable could be wound effectively into these quadrupole coils, with a minimum bending radius of 5 $\mathrm{mm}$ at the inner pole.

\section{CABLING PARAMETER OPTIMIZATION STUDIES}

The cable design process starts with the strand parameters (in this case, the existing SSC wire), and the desired operating current, which determines the number of strands in the cable. Using this input, the maximum allowable keystone angle and the percent compaction can be determined. These limits are set according to the experience on previous cables. As pointed out above, an additional constraint in this case is the requirement that both cables be the same width. This constraint results in cables that are not optimized with respect to the number of strands and the percent compaction. Consequently, a cabling parameter optimization study was performed in order to determine the cable parameter set that would produce a cable with minimum Ic degradation and good coil winding characteristics.

\section{A: Cable manufacturing tests}

Details of this optimization study were reported in [3]. The initial design for the inner cable was based on 38 strands and a compaction of $91 \%$. However, the Ic of this cable was seriously degraded (about 40\%), so two alternative cables 
were produced. In the first case, the compaction was reduced to $89 \%$ by removing one strand. In the other, the compaction was reduced to $90 \%$ by increasing the cable width. The Ic measurements on these cables showed that the Ic degradation was minimal in both cases, and that the study could move on to the next test, which was coil winding. Likewise, a series of outer layer cables were produced by varying the number of strands and the cable width. The final cable parameters for inner and outer cables are listed in Table I.

\section{B: Coil winding tests}

Winding a $15 \mathrm{~mm}$ wide, keystoned cable into a cosine theta type coil with a $15 \mathrm{~mm}$ diameter island is a new experience, so extensive coil winding trials were conducted in order to evaluate the winding problems. These tests showed that both coils could be wound successfully; however, there was a favorable winding direction with respect to the cable twist direction (see Sect. IV). The preferred cable twist for the inner coil was opposite to the twist direction of the SSC cables. This meant that most of the SSC inner wire inventory, which was at final size and twisted in the wrong direction, could not be used for the HGQ coils. Some SSC wire was held at an intermediate size, and thus could be processed to final size with the correct twist direction. New wire for inner coils was procured from Alstom.

Another issue to be resolved was interstrand resistance. The existing inventory of SSC wire has a copper surface, without any coating. In addition, the wire was obtained from 6 different manufacturers, and had been in storage for 5 years, so the thickness of oxide coating varied. In order to evaluate the interstrand resistance, cables were made with wires from the different manufacturers and, in addition, several cables were prepared with stabrite coatings ( $\mathrm{Sn}-5 \% \mathrm{Ag}$ ) and used in one of the model magnets. Although the stabrite coating gave a uniform interstrand resistance, the value was low and resulted in a high ramp rate sensitivity [4]. CERN [5] was developing a procedure for raising the interstrand resistance of cables made with stabrite coated wire; however, the technology transfer of the process to industry was not complete at the time cable production was begun. Consequently, an approach previously developed and demonstrated for the RHIC project was adopted for the HGQ cable. This process develops a reproducible interstrand resistance during the coil curing process by using a two-step curing cycle, first curing the coil at $190 \mathrm{C}$ and low pressure, followed by a $135 \mathrm{C}$ high pressure step. This procedure allows a copper oxide layer to develop on the strands and provides an acceptable interstrand resistance [6].

\section{PRODUCTION CABLING}

Cable for the nine short model magnets and the first long prototype magnet was made at LBNL. Subsequently, cable for the production series magnets was made at New England Electric Wire (NEEW). Production cabling trials were begun in Jan. 2000 on the existing NEEW 48-strand cabling machine, which had been used successfully to manufacture the 30-strand RHIC cable. However, several problems with this cabling machine contributed to a poor yield of acceptable cable. Since a new 48-strand cabling machine (originally built for the SSC project) was in storage at LBNL, NEEW agreed to install this cabler for this project (Fig.1). This machine was installed in Fall 2000 and production work was begun in Jan. 2001. NEEW used this machine to manufacture both inner (37 strand) and outer (46 strand) cables. The cabling speed is 5 meters $/ \mathrm{min}$., and the capacity is 14 unit lengths of cable (the unit length is $180 \mathrm{~m}$ for the inner cable, and $200 \mathrm{~m}$ for the outer cable). To date, NEEW has manufactured over $11,000 \mathrm{~m}$ (58 unit lengths) of inner and over 13,000 m (63 unit lengths) of outer layer cable.

The critical current (Ic) results for the inner cable are shown in Fig 2, and the Ic values for the outer cable are shown in Fig. 3. All production inner cables have met the Ic specification of $14 \mathrm{kA}$ at $7 \mathrm{~T}$ and $4.2 \mathrm{~K}$, except for the first cable which was produced on the old cabling machine and had an Ic of $13.98 \mathrm{kA}$. All production outer cables have met the Ic specification of $8.5 \mathrm{kA}$ at $7 \mathrm{~T}$ and $4.2 \mathrm{~K}$, with the exception of the first three. The Ic of the strands used in this cable were rechecked and found to be lower than the manfacturer's reported values, and lower than the minimum SSC specification. Subsequently, Ic values were measured on all wire in SSC inventory and any wire with low Ic values were set aside. Following this change, all cables made at NEEW have met the Ic specification.

Cable dimensions were checked with the in-line cable measuring machine, and the results are shown in Figs 4 and 5 for the outer cable thickness and keystone angle. The horizontal lines indicate the specification limits for the cable dimensions, the points indicate the average values for each cable run, and the vertical lines indicate the +/- 3 standard deviation values. The width, thickness, and keystone angle values are all within specification for the outer cables. The average values for the keystone angle and the mid-thickness were all within the specification range for the inner layer cables (Figs. 6 and 7). However, for cables 8, 9, and 15, there was a periodic fluctuation that is shown as an increase in the standard deviation values. This was traced to poor control of the turkshead roll temperature, and the controller was modified to provide proper control (to +/- 0.6 C). After this, all inner cable dimensions were within the specification limits.

\section{COIL WINDING RESULTS}

To date, a total of 71 short inner coils and 64 short outer coils have been wound. Initially, practice coils were wound in order to gain experience in handling these cables and to establish the relationship between cable dimensions and the coil dimensions. Short inner coils were wound with both right lay cable and left lay cable. Of the 36 coils fabricated with right lay cable, 34 coils were found to be acceptable 
from the electrical standpoint, and 2 coils have turn-to-turn shorts. However, of the 35 coils fabricated with left lay cable, 9 were rejected due to popped strands in the first turn at the coil ends, which can lead to turn-to-turn shorts. Consequently, a right lay cable, left twist strand specification was adoped for the inner cable. A total of 64 outer layer coils were wound for the short magnet program. All were made from left lay cable, wound in the favorable winding direction, and all were acceptable from the electrical standpoint. Complete details for the short coil fabrication program can be found in [7].

Long coil fabrication began in April 2000. To date, 28 inner coils and 27 outer coils have been completed. The first 5 inner coils were wound from cable remaining from the short model program and were used as "practice " coils. The next 10 were wound from the first spool of production cable, which was somewhat unstable due to one strand that tended to pop out of the cable. One of these coils was rejected due to a popped strand. The 12 most recently wound coils were made from cable made on the new cabling machine, and none of the coils have been rejected due to problems related to the cable. The long outer coils have shown similar experience. The last 11 outer coils have been wound with the NEEW production cable with no rejections due to cable problems.

\section{MAGNET TEST RESUlts}

The results of the short model coil program, including magnet training and field homogeneity measurements, have been reported previously [4,7]. Some of the earlier short models required many training quenches to reach the minimum operating current. These results prompted a number of design changes, after which the training performance was acceptable. The final 5 model magnets achieved a gradient of over $230 \mathrm{~T} / \mathrm{m}$, which provides some margin over the required operating gradient of $215 \mathrm{~T} / \mathrm{m}$. The first long prototype magnet has been tested recently, and the performance will be reported in these proceedings [8]. These results indicate that the Ic specifications established for both inner and outer layer cables are adequate to meet the required field gradient.

\section{SUMMARY}

1. Cable required for the short model program has been completed, and the final series of short model magnets performed satisfactorily.

2. Cable manufacturing is underway for the production series long magnets, with approximately 60 of the required 90 unit lengths of each type complete at this time.

3. The experience gained here demonstrates that a high aspect ratio Rutherford-type cable can be manufactured successfully, but this requires some special equipment.

\section{ACKNOWLEDGMENT}

The Authors wish to thank their colleagues for assistance in the following areas: Ic testing at BNL; cable manufacturing at LBNL; cable manufacturing at NEEW; coil winding at FNAL.

\section{REFERENCES}

[1] A. Yamamoto et al. "Design Study of a Superconducting Insertion Quadrupole Magnet for the Large Hadron Collider", IEEE Transactions on Applied Superconductivity, vol. 7, pp. 747-750, June 1997.

[2] R. Bossert et al., "Development of a High Gradient Quadrupole for the LHC Interaction Regions", IEEE Transactions on Applied Superconductivity, vol. 7, pp. 751-754, June 1997.

[3] R. M. Scanlan et al., "Design and Fabrication of a High Aspect Ratio Cable for a High Gradient Quadrupole Magnet,", IEEE Transactions on Applied Superconductivity, vol.7, pp. 936-938, June 1997.

[4] N. Andreev et al., "Status of the LHC Inner Triplet Quadrupole Program at Fermilab," IEEE Transactions on Applied Superconductivity, vol. 11, pp. 1558-1561, March 2001.

[5] D. Richter et al., "Strand Coating for the Superconducting Cables of the LHC Main Magnets," IEEE Transactions on Applied Superconductivity, vol.9, pp735-741, June 1999.

[6] M.D. Sumption et al., "Influence of strand surface condition on interstrand resistance and coupling loss in NbTi-wound Rutherford cables," Cryogenics, vol 39, pp197-208, 1999.

[7] N. Andreev et al., "Study of Kapton Insulated Superconducting Coils Manufactured for the LHC Inner Triplet Model Magnets at Fermilab," IEEE Transactions on Applied Superconductivity, vol. 10, pp.119-122, March 2000.

[8] R. Bossert et al., "Quench Performance and Mechanical Behavior of the First Fermilab-built Prototype High Gradient Quadrupole for the LHC Interaction Regions," paper MOOR3A-03,these proceedings. 


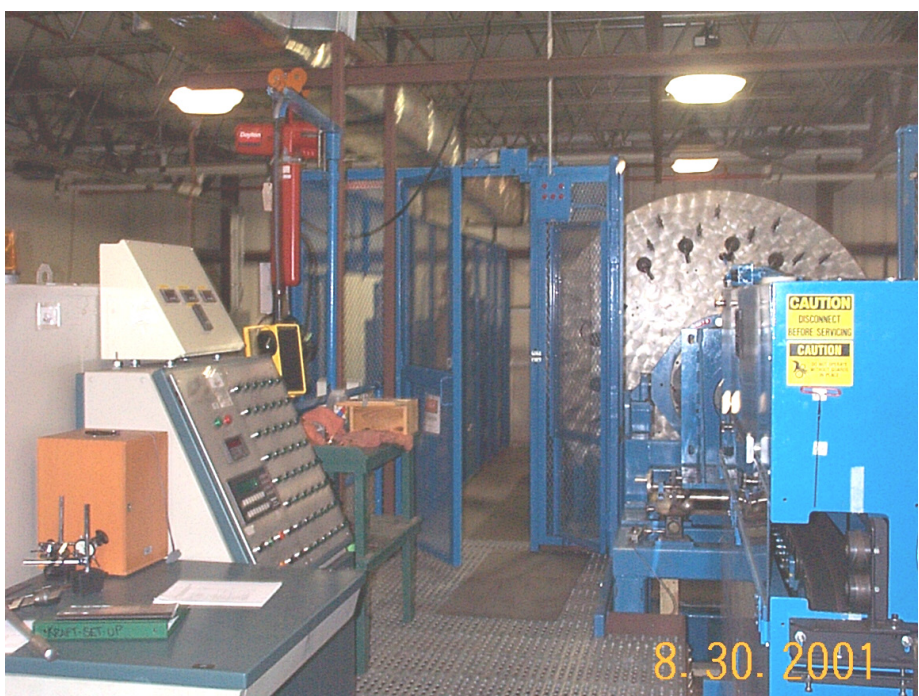

SC-MAG 769

Outer Cable Angle \pm 3 StDev

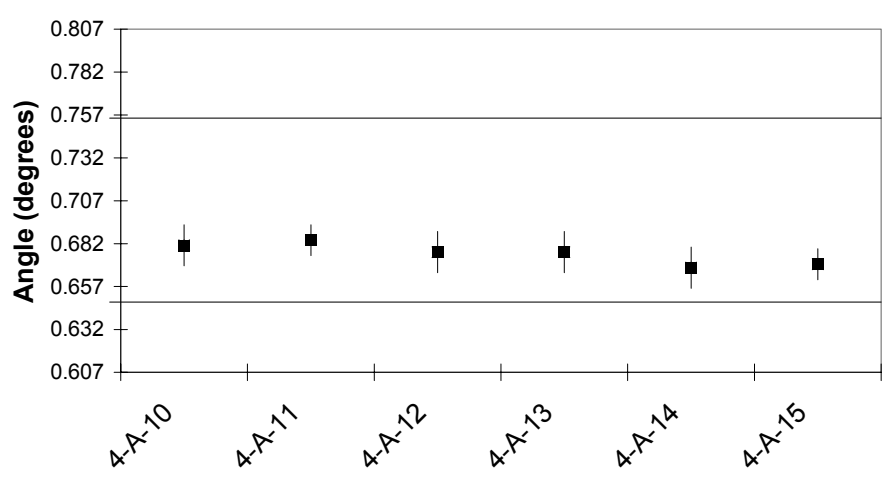

Cable ID

manufacture of HGQ cables.

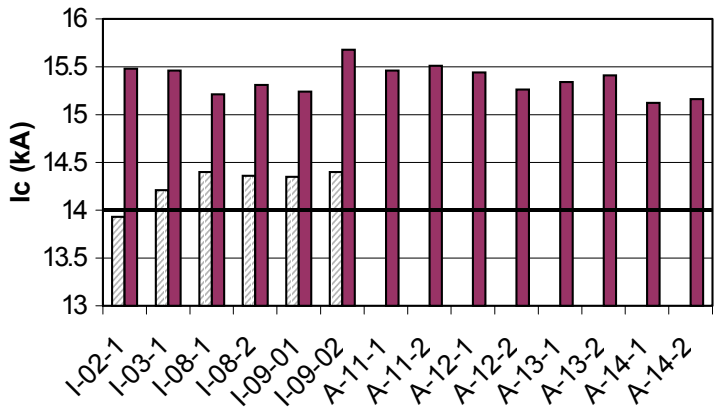

Cable Sample

Fig. 1. 48-strand cabling machine installed at New England Electric wire for

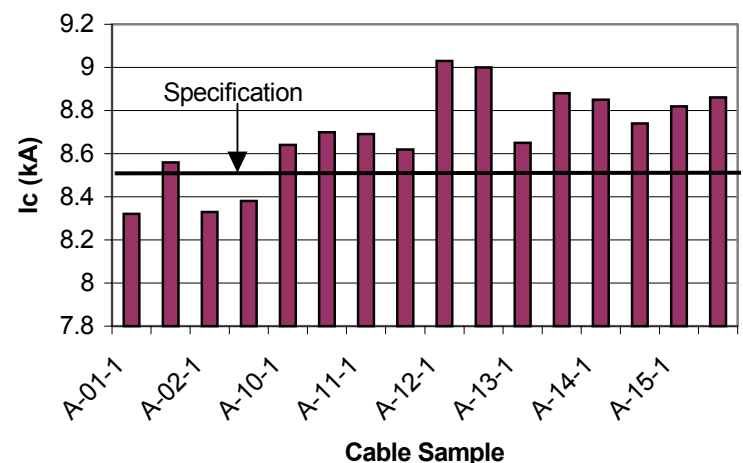

Fig. 2. Ic data for production series inner cables made at NEEW. Fig. 3. Ic data for production series outer cables made at NEEW.

Fig. 4. Mid-thickness for production series outer cables made at NEEW.

Fig. 5. Keystone angle for production series outer cables made at NEEW.

\begin{tabular}{|c|c|c|c|c|c|}
\hline \multirow{2}{*}{ Parameter } & \multirow{2}{*}{ Unit } & \multicolumn{2}{|c|}{ Inner cable } & \multicolumn{2}{c|}{ Outer cable } \\
\cline { 3 - 6 } & & Value & Tolerance & Value & Tolerance \\
\hline Number of strands & & 37 & - & 46 & - \\
\hline Cable width & $\mathrm{mm}$ & 15.40 & \pm 0.025 & 15.40 & \pm 0.025 \\
\hline Minor edge & $\mathrm{mm}$ & 1.320 & & 1.051 & \\
\hline Cable Mid-thickness & $\mathrm{mm}$ & 1.465 & \pm 0.006 & 1.146 & \pm 0.006 \\
\hline Major edge & $\mathrm{mm}$ & 1.610 & & 1.241 & \\
\hline Keystone angle & $\mathrm{degree}$ & 1.079 & \pm 0.05 & 0.707 & \pm 0.05 \\
\hline Transposition length & $\mathrm{mm}$ & 114 & \pm 5 & 102 & \pm 5 \\
\hline Lay direction & & Right & - & Left & - \\
\hline Minimum critical current & $\mathrm{kA}$ & 14.0 & - & 8.5 & - \\
\hline Minimum unit length & $\mathrm{m}$ & 180 & - & 200 & - \\
\hline Residual twist & $\mathrm{degree}$ & $0-90$ & & $0-90$ & \\
\hline Minimum bending radius & $\mathrm{mm}$ & 7 & & 15 & \\
\hline
\end{tabular}




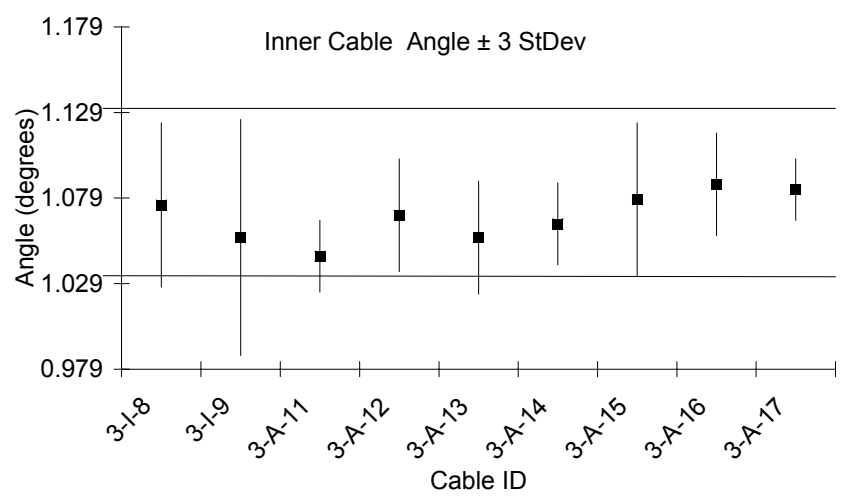

Fig. 6. Keystone angle for production series inner cables made at NEEW.

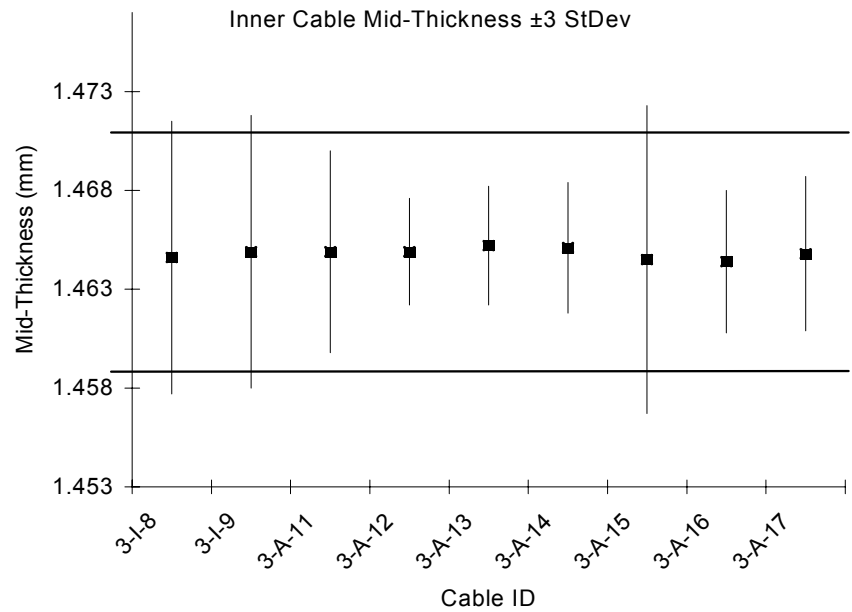

Fig. 7. Mid-thickness for production series inner cables made at NEEW. 